\title{
Physical Properties of Bedding That May Increase Risk of Sudden Infant Death Syndrome in Prone-Sleeping Infants
}

\author{
JAMES S. KEMP, VERNA E. NELSON, AND BRADLEY T. THACH \\ Edward Mallinckrodt Department of Pediatrics, St. Louis Children's Hospital, \\ Washington University School of Medicine, St. Louis, Missouri 63110
}

\section{ABSTRACT}

Soft bedding has been shown in epidemiologic studies to increase the risk for sudden, unexpected death in pronesleeping infants. We compared the physical properties of conventional bedding to bedding from two sources: 1) bedding that covered the airways of victims of sudden infant death syndrome (SIDS) lying prone and face down at the time of death; and, 2) bedding associated with increased risk for SIDS in case-control studies (i.e. bedding filled with ti tree bark). Using simple mechanical models and the head from an infant mannequin, we measured the resistance to airflow, malleability, and capacity to limit $\mathrm{CO}_{2}$ dispersal of the bedding. We also describe a technique for quantifying bedding softness. The resistance and malleability were similar for the conventional bedding, the ti tree bedding, and the bedding from SIDS deaths (analysis of variance, $p=0.85$ and 0.16 ). The ti tree bedding and the other bedding from SIDS cases differed from conventional bedding in two physical properties. Both groups were

Many published reports have indicated that the type of bedding an infant sleeps on may increase the risk for SIDS. These reports include 1) two epidemiologic casecontrol studies indicating that soft bedding increases SIDS risk $(1,2) ; 2)$ case histories of SIDS deaths where bedding covering the victim's airway conceivably produced asphyxia (3-5); and, 3) physiologic reconstructions modeled from the death-scene investigation in cases diagnosed as SIDS, where the relation of the bedding to the victim's airway at the time of death created an asphyxiating environment (6-9). That bedding type and infant sleep position are likely related factors in SIDS is emphasized in a recent report from Australia (2) showing that bedding filled with bark from the ti tree increases the risk of SIDS by 10 -fold, but only in prone-sleeping infants.

Received November 16, 1993; accepted February 25, 1994.

Correspondence: J. S. Kemp, M.D., St. Louis Children's Hospital, 1 Children's Place, St. Louis, MO 63110.

Supported by a grant (HD-10993) from the National Institute of Child Health and Human Development. softer $(p \leq 0.005)$ and limited $\mathrm{CO}_{2}$ dispersal to a greater degree $(p \leq 0.009)$. The finding that increased capacity to limit $\mathrm{CO}_{2}$ dispersal is a consistent property of the bedding covering the airways of these SIDS victims and of bedding shown to be an epidemiologic risk factor for SIDS supports rebreathing of expired air as a mechanism underlying the association of certain kinds of bedding with SIDS. (Pediatr Res 36: 7-11, 1994)

$\quad$ Abbreviations
SIDS, sudden infant death syndrome
$\mathbf{R}$, resistance to airflow
t'1/2, half-time for $\mathrm{CO}_{2}$ disappearance
ANOVA, analysis of variance
group 1A, bedding from prone, face-down SIDS cases
group 1B, bedding filled with bark from the ti tree
group 2, conventional bedding

Moreover, other studies $(1,10)$ indicate that approximately $35 \%$ of infants who die of SIDS while sleeping prone die with their faces turned down into their bedding, a position recently shown to cause marked rebreathing in healthy sleeping infants. $(11,12)$ These several reports, and the case-control studies in particular, indicate important associations among SIDS, type of bedding, and sleep position. The mechanism underlying these apparent associations, however, is not well established.

A major problem in addressing the SIDS and bedding issue is describing and measuring bedding characteristics. Previous reports have suggested many different physical properties of bedding that might play a role in sudden, unexpected infant death. These properties include high resistance to airflow (13-15) or low resistance when associated with increased softness, malleability, and porosity causing retention of expired air $(2,6)$.

In the past, comparative analyses of bedding were difficult because quantitative methods were not available. In the present studies, we have used new techniques that 
allow us to measure and compare bedding physical properties. Our hypotheses are as follows: 1) items of bedding found covering the airways of prone SIDS victims have certain potentially hazardous properties that are similar to the ti tree bark bedding that increases SIDS risk in prone-sleeping infants (2); and, 2) most or all bedding from these cases will differ from conventional bedding with respect to these properties. To make these comparisons, we measured softness, malleability, $R$, and limitation of $\mathrm{CO}_{2}$ dispersal (as an indirect estimate of porosity) for 18 different items of bedding.

\section{METHODS}

\section{Bedding Studied}

The bedding studied included the actual bedding or identical bedding from the death scene of infants who were found face down in their bedding and whose death was attributed to SIDS. This bedding included a waterbed covered by a comforter, as described in a case report (5), three different polystyrene bead-filled cushions (6), a sheepskin (7), and seven items from a local study of SIDS in St. Louis (8). These first 12 items of bedding will be referred to subsequently as group $1 \mathrm{~A}$. The ti tree barkfilled products (group 1B) used were a cradle mattress and pillow (Tetra, Basically Baby, New South Wales, Australia). Bark from the ti tree has the consistency of the outer "paper" layer of birch bark, and when used in bedding is in the form of chips 1 to $3 \mathrm{~cm}$ in diameter. Unless specific information was lacking, bedding associated with infant deaths was arranged for laboratory study as it had been beneath the baby at the time of death, as described in previous publications (7-9).

Conventional "firm" bedding (group 2) included the following: 1) a crib mattress made of foam rubber and covered tightly with a plastic protector (Ortho-Baby, Kolcraft Enterprises, Inc., Chicago, IL; 2) a crib mattress made of steel coils and covered with synthetic woven material (Simmons Baby Beauty Rest Backcare VI, Juvenile Products Company, New London, WI); and 3) two hospital bassinet mattresses (Bassinet Pads, BG Industries, Northridge, CA). The conventional mattresses were covered with a single smooth cotton sheet tucked in beneath them.

\section{Bedding Physical Properties}

Except for the estimate of softness, the techniques for measuring physical properties have been described in detail elsewhere $(6,7,16)$. All measurements were repeated five times for each item of bedding.

Softness. The principle used to develop the measure of softness was that a spherical object placed on soft bedding would be in contact with a wider area than if placed on a firm item. To perform these studies, the head from an infant resuscitation mannequin (Resusci Baby, Armstrong Medical Instruments, Lincolnshire, IL) was weighted to approximate the density of human tissue (6,
$7,17)$. For group 1A bedding, the mannequin's head was placed in the position of the infant's head at the time of death, as noted in previous publications (6-9); in most cases, the mannequin's nose and mouth were directly down into the bedding studied. We had no detailed scene information from the deaths on ti tree bark products (group 1B), although face-down deaths are common in the part of Australia where ti tree mattresses are used (18). We arbitrarily chose the face straight-down position to study this bedding, with no blankets interposed between the mannequin head and the mattress cover. For the conventional firm bedding (group 2), the mannequin head was positioned with face straight down.

The curvilinear line of contact of the bedding with the face was then traced onto the mannequin's face using a fine-tipped marker. Next, the mannequin's head was lifted from the bedding, revealing the facial surface inside the marks made by the marker (Fig. 1). By a series of transfers using tracings on transparent tape, the irregular map was transferred to graph paper and the area measured.

Malleability. The depth of the pocket persisting in the bedding for $30 \mathrm{~s}$ after the mannequin head was lifted off



Figure 1. Softness estimated using the area of the face in contact with bedding. Curvilinear points of contact of bedding with the mannequin's face are indicated by black lines. The measurement was made with the mannequin on a comforter over a pillow (item of bedding No. 8). The drawing shown was superimposed on graph paper, and the area within the black line boundaries was calculated. 
was used to describe the bedding's malleability (6). This measurement reflects the bedding's propensity to retain an altered contour in response to the mass of the mannequin's head.

$\boldsymbol{R}$. The change in pressure needed to create flow of 0.2 $\mathrm{L} / \mathrm{s}$ through the mannequin's nares was used to calculate the $\mathrm{R}$ imposed by the bedding $(7,8,15)$.

Limitation of $\mathrm{CO}_{2}$ dispersal. The mannequin's head was positioned as specified above. A $100-\mathrm{mL}$ syringe filled with $5 \% \mathrm{CO}_{2}$ was attached to the mannequin's airway, and the $\mathrm{CO}_{2}$ was washed out of this system using repetitive $30-\mathrm{mL}$ " "breaths." The $\mathrm{t} 1 / 2$ for disappearance of $\mathrm{CO}_{2}$ from this system was used to quantify limitation on $\mathrm{CO}_{2}$ dispersal imposed by the bedding (16).

\section{Statistical Analysis}

For these analyses, the bedding was grouped into three categories: group 1A, group 1B, and group 2. The coefficients of variation for the softness measurements are presented in Results. ANOVA was used to identify differences among the three groups for each of the four bedding properties. Post-hoc comparisons between two groups were carried out using the unpaired $t$ test, with the Bonferroni-Dunn correction. $p$ values $<0.05$ were considered significant.

\section{RESULTS}

All descriptive statistics are mean \pm SD. The results are presented in Table 1 and Figure 2.

Softness. The softness measurements for each of the groups were as follows: group $1 \mathrm{~A}, 65.9 \pm 23.1 \mathrm{~cm}^{2}$; group $1 \mathrm{~B}, 97.8 \pm 14.7 \mathrm{~cm}^{2}$; and group $2,14.7 \pm 3.0 \mathrm{~cm}^{2}$. There were significant differences in the quantitative measurement of softness among the three groups of bedding (ANOVA, $p=0.0004$ ). With direct comparison, both groups of bedding linked with SIDS (group 1A bedding and group $1 \mathrm{~B}$ bedding) were shown to be softer than conventional bedding ( $p=0.003$ and 0.005 , respectively). The difference between group $1 \mathrm{~A}$ bedding and group $1 \mathrm{~B}$ bedding was not significant.

The coefficients of variation for the estimates of softness (area in contact with the mannequin's face) for each item of bedding ranged from 2.9 to $29.0 \%$ (mean $\pm \mathrm{SD}=$ $11.8 \pm 7.4 \%$ ).

Malleability. The malleability for the group $1 \mathrm{~A}$ bedding was $2.3 \pm 2.5 \mathrm{~cm}$, and for ti tree bedding (group 1B) it was $3.3 \pm 1.5 \mathrm{~cm}$. Although the four items of conventional bedding were not malleable (pocket depth $=0.0 \pm$ $0.0 \mathrm{~cm})$, the differences among the three groups were not statistically significant (ANOVA, $p=0.16$ ). However, as can be seen in Table 1 and Figure 2, several of the items associated with sudden infant deaths had marked malleability, e.g. polystyrene cushions, a ti tree cradle mattress, and a comforter on a pillow. Items that were soft also tended to be malleable $(p=0.0014)$, but the association was variable $\left(r^{2}=0.48\right)$.

$\boldsymbol{R}$. The differences in $\mathrm{R}$ among the three groups were not significant (ANOVA, $p=0.8514$ ). The values for $R$ were as follows: 1) group 1A bedding, $14.4 \pm 4.5 \mathrm{~cm}$ $\mathrm{H}_{2} \mathrm{O} / \mathrm{L} / \mathrm{s}$; 2) group $1 \mathrm{~B}$ (ti tree bedding), $15.2 \pm 5.2 \mathrm{~cm}$ $\mathrm{H}_{2} \mathrm{O} / \mathrm{L} / \mathrm{s}$; and 3) group 2 (conventional bedding), $13.3 \pm 0.9$ $\mathrm{cm} \mathrm{H}_{2} \mathrm{O} / \mathrm{L} / \mathrm{s}$.

Limitation of $\mathrm{CO}_{2}$ dispersal $\left(t^{1 / 2}\right)$. The $\mathrm{t}^{1 / 2}$ results were as follows: 1) group $1 \mathrm{~A}$ bedding, $31.4 \pm 8.4 \mathrm{~s}$; 2) ti tree bedding (group 1B), $37.5 \pm 1.6 \mathrm{~s}$; and 3) group 2 bedding (conventional), $18.7 \pm 1.7 \mathrm{~s}$. There were marked differences among the groups in their propensity to limit $\mathrm{CO}_{2}$ dispersal (ANOVA, $p=0.0113$ ). Once again, group 1A and $1 \mathrm{~B}$ bedding (the bedding linked to SIDS) differed from conventional bedding ( $p$ values 0.008 and 0.009 ,

Table 1. Physical properties of bedding

\begin{tabular}{|c|c|c|c|c|}
\hline Bedding & $\begin{array}{l}\text { Softness } \\
\left(\mathrm{cm}^{2}\right)\end{array}$ & $\begin{array}{l}\text { Malleability } \\
(\mathrm{cm})\end{array}$ & 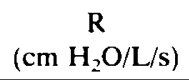 & $t 1 / 2(s)$ \\
\hline \multicolumn{5}{|l|}{ Group 1A } \\
\hline 1. Polystyrene cushion 1 & $90.7 \pm 12.3$ & $8.7 \pm 0.9$ & $12.0 \pm 2.5$ & $38.7 \pm 7.1$ \\
\hline 2. Polystyrene cushion 2 & $82.5 \pm 6.4$ & $4.7 \pm 1.1$ & $8.0 \pm 2.6$ & $38.9 \pm 8.4$ \\
\hline 3. Polystyrene cushion 3 & $65.1 \pm 6.4$ & $3.4 \pm 0.8$ & $19.4 \pm 3.1$ & $28.1 \pm 3.6$ \\
\hline 4. Sheepskin & $97.1 \pm 6.4$ & $2.9 \pm 0.6$ & $16.1 \pm 3.9$ & $43.6 \pm 4.1$ \\
\hline 5. Waterbed comforter & 91.9 & $1.9 \pm 0.6$ & $13.3 \pm 3.8$ & $45.8 \pm 5.0$ \\
\hline 6. Comforter/foam pad & $52.4 \pm 3.6$ & $1.5 \pm 0.5$ & $16.5 \pm 4.2$ & $29.1 \pm 3.7$ \\
\hline 7. Cushion/couch & $58.2 \pm 2.6$ & $0.9 \pm 0.2$ & $16.2 \pm 3.9$ & $30.0 \pm 6.2$ \\
\hline 8. Comforter/pillow & $77.1 \pm 3.5$ & $3.5 \pm 1.4$ & $15.7 \pm 3.3$ & $29.9 \pm 6.9$ \\
\hline 9. Bassinet/towel & $64.9 \pm 3.8$ & 0.0 & $22.3 \pm 7.7$ & $19.7 \pm 4.2$ \\
\hline 10. Bassinet/sheet & $23.6 \pm 2.7$ & 0.0 & $13.9 \pm 3.7$ & $22.4 \pm 4.9$ \\
\hline 11. Mattress/sheet & $34.6 \pm 7.8$ & $0.3 \pm 0.1$ & $6.2 \pm 2.1$ & $23.8 \pm 2.2$ \\
\hline 12. Comforter/mattress & $52.9 \pm 1.2$ & 0.0 & $12.3 \pm 3.9$ & $27.4 \pm 3.3$ \\
\hline \multicolumn{5}{|l|}{ Group 1B } \\
\hline 13. Ti tree mattress & $87.4 \pm 8.8$ & $4.4 \pm 0.5$ & $11.5 \pm 2.5$ & $36.4 \pm 4.4$ \\
\hline 14. Ti mattress + pillow & $108.2 \pm 11.8$ & $2.3 \pm 1.9$ & $18.9 \pm 5.4$ & $38.6 \pm 7.3$ \\
\hline \multicolumn{5}{|l|}{ Group 2} \\
\hline 15. Mattress/coil & $11.7 \pm 2.7$ & 0.0 & $14.2 \pm 2.6$ & $20.0 \pm 0.9$ \\
\hline 16. Mattress/foam & $12.6 \pm 2.1$ & 0.0 & $12.6 \pm 2.1$ & $20.2 \pm 1.8$ \\
\hline 17. Bassinet $1 /$ hospital & $15.2 \pm 2.8$ & 0.0 & $12.5 \pm 2.9$ & $17.4 \pm 1.8$ \\
\hline 18. Bassinet $2 /$ hospital & $18.7 \pm 5.4$ & 0.0 & $13.9 \pm 3.2$ & $17.0 \pm 1.6$ \\
\hline
\end{tabular}



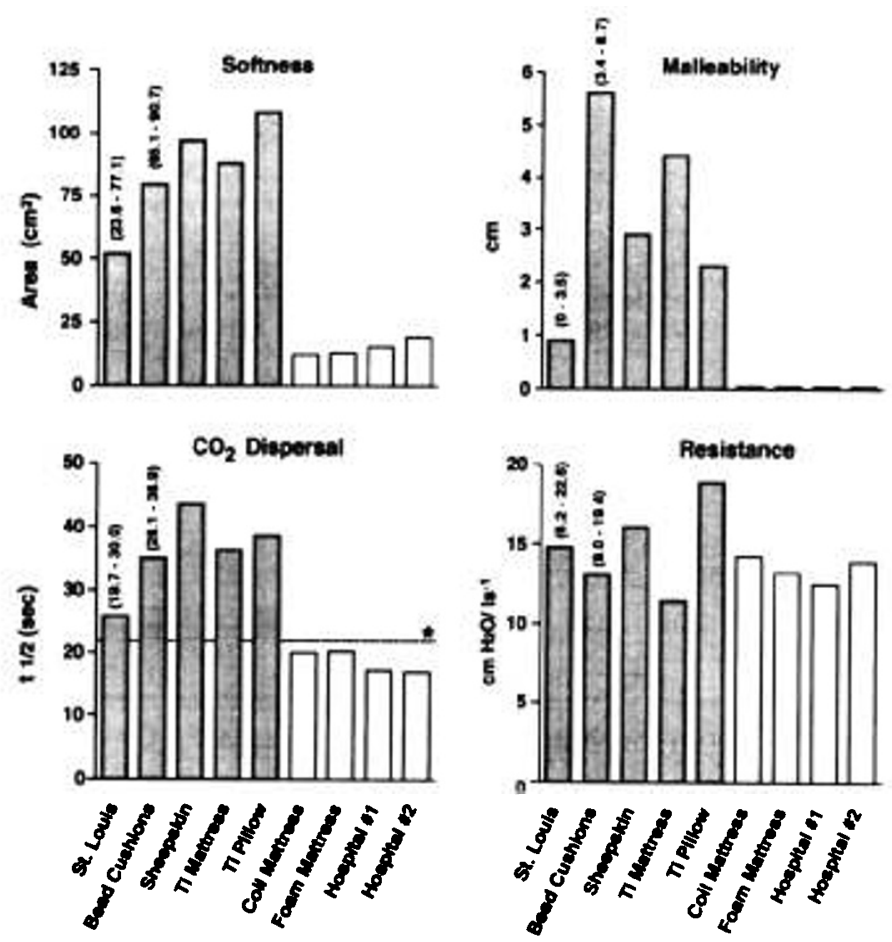

Figure 2. Quantitative estimates of four bedding factors. Shaded bars, groups $1 \mathrm{~A}$ and 1B, items on which infants have died. Open bars, group 2 , standard bedding. St. Louis and bead cushion bars represent the means from seven and three items, respectively; the range of results for those two groups are shown in parentheses. Other bars are for individual items listed in Table 1. *, Line drawn at $t 1 / 2=22.4 \mathrm{~s}$, corresponding to the threshold above which deaths occurred in other studies using a rabbit rebreathing model (15).

respectively). The difference between the group $1 \mathrm{~A}$ bedding and the ti tree bedding was not significant.

\section{DISCUSSION}

Our results describe the physical properties of conventional bedding and of bedding on which infants slept at the time of their death. Ti tree bark-filled bedding, associated with SIDS by case-control studies, is softer and limits $\mathrm{CO}_{2}$ dispersal more than conventional infant bedding. Other items of bedding from SIDS cases (group 1A) also were softer and caused more limitation of $\mathrm{CO}_{2}$ dispersal than conventional bedding and were not statistically different from ti tree bedding with respect to these two properties.

Circular reasoning in our analysis was avoided because physical properties of the bedding did not determine selection for the study; rather, group 1A and $1 \mathrm{~B}$ bedding were all items studied either because they were found over victims airways or associated epidemiologically with SIDS in the prone position. However, the finding that group $1 \mathrm{~A}$ and $1 \mathrm{~B}$ bedding were similar with respect to two properties (softness and limitation of $\mathrm{CO}_{2}$ dispersal) that can potentially create a lethal environment supports the hypothesis that these properties, in any bedding, may be associated with increased SIDS risk.

Many reports have speculated or claimed that soft bedding is dangerous to infants $(1,2,19,20)$, but why softness is dangerous and how to measure it (15) are questions infrequently addressed. In previous reports, we have shown that soft and malleable bedding may seal an infant's face within a dangerous microenvironment (6). Furthermore, even in a dangerous microenvironment, an infant lying with its face straight down will stay in that position longer while on softer bedding than while on firm bedding (11).

In this work, we have used a new method to measure softness. Our method uses the area in contact with the face of an infant mannequin. We have chosen this method to measure softness, instead of measures of changes in bedding thickness in response to weight (15), because we wanted to quantify the capacity of soft bedding to form a barrier around an infant's external airway and thus to create a separate respiratory microenvironment during sleep.

Group $1 \mathrm{~A}$ bedding and ti tree bedding limited $\mathrm{CO}_{2}$ dispersal to a greater degree than conventional bedding, an observation that, coupled with studies of living infants $(11,12)$, suggests that these softer, porous forms of bedding would be more conducive to fatal rebreathing in prone infants who adopt a face-down posture. This conclusion also is based on preliminary work in which we have shown that the $t 1 / 2$ correlates well with the ability of bedding to cause lethal rebreathing of $\mathrm{CO}_{2}$ in a rabbit model (16). Figure 2 shows that both ti tree items limited $\mathrm{CO}_{2}$ dispersal to a degree well above the threshold for lethality in our rabbit model. Furthermore, the $t^{1 / 2}$ for five of seven group II items, but none of the conventional bedding types, exceeded the threshold for lethality (Fig. 2 , Table 1). Thus, the high risk for SIDS associated with ti tree and other forms of soft bedding could be explained by the death-scene evidence indicating that many infants die while lying face down on such bedding and by the animal studies indicating rebreathing as a mechanism of death on bedding with similar physical properties $(2,6-8$, 16).

All bedding studied was of low $\mathrm{R}$, and the $\mathrm{R}$ measured were below levels of $\mathrm{R}$ associated with $\mathrm{CO}_{2}$ retention (21). Similar to softness, low R would be less likely to provoke arousal or efforts to change head position than high R. On the softer bedding, which tends to form a seal around the face, the low $\mathrm{R}$ of the permeable covers would also favor passage of expired air across the larger area of contact with the face and into the bedding rather than into the ambient air over the infant's head, thus favoring rebreathing.

Throughout this report, we have compared the physical characteristics of bedding used by SIDS victims found in the face-down position with conventional "firm" bedding. However, for a number of reasons it is premature to state that the conventional bedding we studied is completely safe for prone-sleeping infants (20). First, firm bedding may be more likely than soft to cause airway occlusion by nasal compression (22) or retroposition of the mandible $(23,24)$ in prone-sleeping infants. Second, for prone-sleeping infants, some degree of rebreathing may 
occur even on firmer bedding (9). For example, inspired $\mathrm{CO}_{2}$ percentage $\geq 1 \%$ has been recorded when babies on firm bedding turn their heads from face-to-side to face down $(11,12)$, and the $t \frac{1}{2}$ of the conventional foam and coil mattresses predict at least some rebreathing on them for the rabbit model mentioned above (16).

Other mechanisms of death related to bedding, besides rebreathing, are possible. Some reports have emphasized the risk of bedding of high $\mathrm{R}$ causing acute airway occlusion $(13,14)$. Although these types of sudden asphyxial deaths seem to occur (25), the bedding we studied was of low $\mathrm{R}$. Other authors have proposed that allergic responses might explain bedding deaths (2). The varied composition of the bedding that we studied, however, suggests that if an abnormal immunologic response occurs, it is not likely to be specific for the natural or synthetic fibers making up the bedding. Finally, soft bedding with thick filling used by infants sleeping prone may add to potential thermal stress, a contributory mechanism for SIDS postulated in some studies (18).

It is apparent from this study that infant bedding from SIDS victims found in the face-down position shares certain properties and differs from conventional bedding with respect to softness, limitation of $\mathrm{CO}_{2}$ dispersal, and, in some cases, malleability. Furthermore, the consistent propensity of the bedding studied to limit $\mathrm{CO}_{2}$ dispersal suggests that rebreathing of expired air may be a common mechanism for the death of prone-sleeping infants on particular types of bedding.

\section{REFERENCES}

1. Carpenter RG, Shaddick CW 1965 Role of infection, suffocation, and bottle feeding in cot death: an analysis of some factors in the histories of 110 cases and their controls. Br J Prev Soc Med 19:1-7

2. Ponsonby A-L, Dwyer T, Gibbons LE, Cochrane JA, Wang Y-G 1993 Factors potentiating the risk of sudden infant death syndrome associated with the prone position. N Engl J Med 329:377-382

3. Abramson H 1944 Accidental mechanical suffocation in infants. J Pediatr $25: 404-413$
4. Bass M, Kravath RE, Glass L 1986 Death-scene investigation in sudden infant death. N Engl J Med 315:100-105

5. Gilbert-Barness E, Hegstrand L, Chandra S, Emery JL, Barness LA, Franciosi R, Huntington R 1991 Hazards of mattresses, beds, and bedding in deaths of infants. Am J Forensic Med Pathol 12:27-32

6. Kemp JS, Thach BT 1991 Sudden death in infants sleeping on polystyrenefilled cushions. N Engl J Med 423:1858-1864

7. Kemp JS, Thach BT 1993 A sleep position-dependent mechanism for infant death on sheepskins. Am J Dis Child 147:642-646

8. Kemp JS, Kowalski RM, Burch PM, Graham MA, Thach BT 1993 Unintentional suffocation by rebreathing: a death scene and physiologic investigation of a possible cause of sudden infant death. J Pediatr 122:874-880

9. Bolton DPG, Taylor BJ, Campbell AJ, Galland BC, Cresswell C $1993 \mathrm{Re}$ breathing expired gases from bedding: a cause of cot death. Arch Dis Child 69:187-190

10. Taylor BJ 1991 A review of epidemiologic studies of sudden infant death syndrome in southern New Zealand. J Paediatr Child Health 27:344-348

11. Chiodini BA. Thach BT 1993 Impaired ventilation in infants sleeping face down: potential significance for sudden infant death syndrome. J Pediatr 123:686-692

12. Chiodini BA, Kemp JS, Thach BT 1994 Responses of prone-sleeping infants to rebreathing caused by soft porous bedding. Pediatr Res 35:390A(abstr)

13. Golin M 1959 Medicine and the press: a case of joint effort to sound an alarm. JAMA 169:2021-2022

14. Emery JL, Thorton JA 1968 Effects of obstruction to respiration in infants, with particular reference to mattresses, pillows, and their coverings. Br Med J [Clin Res] 3:209-213

15. British Standards Institution 1970) Specification for Performance Require ments for Hardness of, and Air Flow Through, Infant Pillows, BS 4578. British Standards House, London

16. Kemp J, Thach B 1992 New method for quantifying asphyxial rebreathing prior to death in "SIDS" infants. FASEB J 6:1703A(abstr)

17. Mountcastle VB, ed. 1980 Medical Physiology, 14th Ed. CV Mosby, St. Louis, p 1369

18. Ponsonby A-L, Dwyer T, Gibbons LE, Cochrane JA, Jones ME, McCall MJ 1992 Thermal environment and sudden infant death syndrome: case-control study Br Med J [Clin Res] 304:277-282

19. Sinal SH, Stanton WA 1979 Infant strangulation in a mesh portable crib. Pediatrics 63:669-670

20. Orenstein SR 1992 Throwing out the baby with the bedding: a commentary on the A.A.P. statement on positioning and SIDS. Clin Pediatr (Phila) 546-548

21. Tan S, Duara S, Neto GS, Afework M, Gerhardt T, Bancalari E 1992 The effects of respiratory training with inspiratory flow resistive loads in premature infants. Pediatr Res 31:613-618

22. Swift PGF, Emery JL 1973 Clinical observations on response to nasal occlusion in infancy. Arch Dis Child 48:947-951

23. Cross KW, Lewis SR 1971 Upper respiratory obstruction and cot death. Arch Dis Child 46:211-213

24. Stark AR, Thach BT 1976 Mechanisms of airway obstruction leading to apnea in newborn infants. J Pediatr 89:982-985

25. Kraus JF 1985 Effectiveness of measures to prevent unintentional deaths of infants and children from suffocation and strangulation. Public Health Rep 100:231-240 